\title{
MIGRAÇÃO E COLONIZAÇÃO DA TRANSAMAZÔNICA NA OBRA DE ODETTE DE BARROS MOTT
}

\author{
José Valtemir Ferreira da Silva ${ }^{1}$ \\ Francisco Pereira Smith Júnior ${ }^{2}$ \\ Aline Costa da Silva ${ }^{3}$
}

\begin{abstract}
RESUMO
O presente estudo visa refletir sobre processo migração para a Amazônia em virtude da colonização da rodovia Transamazônica na década de 1970 a partir da análise da obra A Transa Amazônica (a grande ilusão), da escritora Odette de Barros Mott. A abordagem toma como ponto de partida a obra literária e a consulta de livros, jornais e fontes que discutem a temática da migração, com vistas a proporcionar uma discussão de forma a dialogar com as questões expostas na narrativa. Assim, vê-se que foram apresentados pontos relevantes da migração e colonização da Transamazônica que permitem uma análise do cotidiano da rodovia a partir da literatura. Diante do exposto, tal abordagem contribui para reiterar a importância da autora para literatura nacional, e de colaborar para os diversos trabalhos sobre os grandes projetos da Amazônia.
\end{abstract}

Palavras-chave: Transamazônica. Literatura. Imigração. Colonização.

\begin{abstract}
The present study aims to reflect on migration process for the colonization of the Transamazon highway in the 1970s from the analysis of the work Transa Amazônica (the great illusion), by the writer Odette de Barros Mott. Thus the approach takes as its starting point the literary work, and the consultation of books, newspapers and other sources of publication of the time, with a view to providing a discussion in order to dialogue on the issues exposed in the narrative. Thus, it is seen that relevant points of immigration and colonization of the Transamazônica were presented, which allow an analysis of the daily life of the highway from the literature. In view of the above, this approach helps to reiterate the importance of the author for national literature, and to collaborate for the various works on the great projects of the Amazon.
\end{abstract}

Keywords: Transamazônica. Literature. Immigration. Colonization.

\section{INTRODUÇÃO}

Ao se refletir sobre a migração ${ }^{4}$ por ocasião da abertura e colonização da rodovia Transamazônica na década de 1970, pode-se propor uma discussão a partir de vários

\footnotetext{
${ }^{1}$ Mestrando em Linguagens e Saberes da Amazônia (PPLSA/UFPA), email: valtemir@ufpa.br

${ }^{2}$ Professor Adjunto III da Universidade Federal do Pará. Professor e vice-coordenador do Programa de PósGraduação em Linguagens e Saberes na Amazônia da Universidade Federal do Pará - PPLSA/UFPA/Campus Bragança. email: fsmith@ufpa.br

${ }^{3}$ Mestre em Linguagens e Saberes da Amazônia pela Universidade Federal do Pará (PPLSA/UFPA), doutoranda em Estudos Literários pelo Programa de Pós-Graduação em Letras (PPGL-UFPA).email:alineclaucs@ gmail.com

${ }^{4}$ Movimentação de entrada (imigração) ou saída (emigração) de indivíduo ou grupo de indivíduos, ger. em busca de melhores condições de vida [Essa movimentação pode ser entre países diferentes ou dentro de um mesmo país.] cf. emigração e imigração. Sobre o tema consultar Dicionário Houaiss.
} 
contextos, como as histórias de sucesso e insucesso narradas sobre a rodovia, a importância desta para a Amazônia, os sonhos de uma vida melhor que motivaram inúmeras famílias a migrarem, os benefícios e suas problemáticas.

Uma forma peculiar de ter uma visão sobre tais contextos é entender a literatura como fonte documental, e abordar a visão de autores que vivenciaram o referido período, através da forte propaganda ou mesmo presenciando in loco as obras, o processo de colonização e os primeiros anos dos migrantes nas terras das margens da rodovia, tendo em vista que a obra ficcional pode proporcionar uma leitura privilegiada de um dado momento histórico.

Deste modo, será realizada uma análise da obra A Transa Amazônica (a grande ilusão), com subsídio de fontes bibliográficas e jornais que noticiaram sobre a rodovia na década de 1970, além de autores que abordam o fenômeno migratório como Ianni (2004), Haesbaert (2005), Smith Júnior (2011), Sayad (1998), visando demonstrar como ocorreu a migração para a colonização da rodovia a partir da narrativa literária, e expor fatores que notabilizaram e marcaram o referido processo.

Para tanto, primeiramente será feita a contextualização do anúncio da construção e colonização da rodovia Transamazônica expondo alguns aspectos que mobilizaram os primeiros anos da migração e colonização; em seguida, será apresentada a escritora Odette de Barros Mott (1986) e sua obra A Transa Amazônica (a grande ilusão); e por último será realizada uma análise da obra através do contraponto com autores que discutem o fenômeno migratório e outras fontes bibliográficas, concluindo a discussão com as considerações finais.

Assim sendo, a abordagem proporcionará visualizar por uma ótica diferente o projeto de colonização e os primeiros anos de migração da rodovia Transamazônica e assim contribuir e exaltar a importância de tal discussão para o debate sobre a migração que ao longo da história acompanhou as iniciativas e projetos de ocupação, integração e exploração de recursos naturais na Amazônia.

\section{A MIGRAÇÃO NA AMAZÔNIA: A TRANSAMAZÔNICA}

Historicamente a Amazônia passou por momentos importantes ligados à ideia de exploração de seus recursos naturais e de povoamento. Para definir o contexto em que se deram tais ocasiões em que a migração de pessoas das mais diversas partes do País esteve em tela, pode-se utilizar as palavras de Abdelmalek Sayad (1998), que entende: 
ser. E esse trabalho, que condiciona toda a existência do imigrante, não qualquer trabalho, não se encontra em qualquer lugar; ele é o trabalho que o "mercado de trabalho para imigrantes" lhe atribui e no lugar em que lhe é atribuído: trabalhos para imigrantes que requerem, pois, imigrantes; imigrantes para trabalhos que se tornam, dessa forma, trabalhos para imigrantes (SAYAD, 1998, p. 55).

Assim, em conformidade com noção de trabalho e migração acima referida, pode-se traçar também um panorama da Amazônia do século XX, em que os fluxos migratórios estiveram inteiramente entrelaçados com a ideia de trabalho e geração de renda, o que a geógrafa Bertha Becker (2005), resumiu como surtos e declínios ${ }^{5}$, em que por vezes a região estava no foco do desenvolvimento econômico nacional, mobilizando milhares de pessoas das mais variadas regiões do país, inclusive de outras nacionalidades, a procura de trabalho e de melhores condições de vida, como fora os ciclos da borracha ${ }^{6}$, seguidos de momentos de extrema decadência.

Tal conjuntura reforça o caráter transitório/provisório dos fluxos migratórios que principalmente na primeira metade do século XX, motivados pelos incentivos e propaganda do governo, trouxeram milhares de pessoas para a região em busca de trabalho e renda, de um futuro melhor para seus familiares, mas, que tão logo os períodos de apogeu passavam, estas retornavam aos seus lares ou mesmo procuravam outras frentes de trabalho no País.

Deste modo, no final da década de 1960 e início da década seguinte, o processo de migração para a Amazônia entra em pauta mais uma vez, trazendo e impregnando fortemente nos discursos a ideia de ocupação e integração da Amazônia ao território brasileiro. Assim, era preciso não só uma migração com fins de trabalho e renda, mas algo capaz de reter pessoas para o povoamento e que garantisse, entre outras coisas, uma ocupação da Amazônia por brasileiros.

Neste cenário, em junho de 1970, o presidente da república Emílio Garrastazu Médici, após presenciar a situação de miséria do nordeste brasileiro que era fortemente castigado pela seca, teria se comovido e precipitado a assinatura do decreto $\mathrm{n}^{\circ} 1.106$, que criou o Programa de Integração Nacional - $\mathrm{PIN}^{7}$, que dentre outras providências, anunciava artigo $2^{\circ}$, a abertura da rodovia Transamazônica, badalada como uma grandiosa obra para a integração definitiva da Amazônia ao território nacional.

\footnotetext{
${ }^{5}$ Sobre o tema consultar Becker (2005).

${ }^{6}$ Braga (2015), afirma que após o fim do ciclo da borracha ficaram apenas lembranças de uma época áurea, deixando um saldo de milhares de trabalhadores pobres, doentes, uns com e outros sem condições de voltar a sua terra natal.

${ }^{7}$ Aprovado durante a reunião ministerial de 15 de junho de 1970 para ser executado no quadriênio de 1970 1974. A íntegra do decreto $n^{\circ} 1.106$, de 16 de junho de 1970 pode ser consultado em Pereira (1971).
} 
[...] Art. 2. ${ }^{\circ}$ A primeira etapa do Programa de Integração Nacional será constituída pela construção imediata das rodovias Transamazônica e Cuiabá-Santarém.

$\S 1 .^{\circ}$ Será reservada, para colonização e reforma agrária, faixa de terra de até dez quilômetros à esquerda e à direita das novas rodovias para, com os recursos do Programa de Integração Nacional, se executar a ocupação da terra e adequada e produtiva exploração econômica. [...] (PEREIRA, 1971, p. 150)

Assim, ademais a questão da integração e ocupação de uma parte do território vista ao longo do tempo, contraditoriamente, como um vazio ${ }^{8}$ de difícil acesso, o Programa de Integração Nacional anunciado pelo governo vislumbrava resolver uma segunda questão, a situação dos nordestinos que eram fortemente castigados pela seca, e, portanto, estes seriam prioridade no movimento de migração para a colonização as margens da rodovia.

Após o anúncio da construção e colonização da rodovia Transamazônica, o governo disseminou uma forte propaganda acerca do processo, tendo como principal aliada a mídia, e muitas vezes tendo à frente o próprio general-presidente Emílio Garrastazu Médici, que esteve várias vezes in loco acompanhando as obras da estrada, como no ato simbólico da derrubada de uma enorme castanheira, que estabelecia o marco inicial dos trabalhos de construção da grande rodovia, como fora noticiado na edição do dia 10 de outubro de 1970 do jornal Folha de São Paulo:

\begin{abstract}
O presidente emocionado assistiu à derrubada de uma árvore de 50 metros de altura, no traçado da futura rodovia, e descerrou a placa comemorativa do início da construção. [...]Descendo do carro que o conduzia, o presidente hasteou o pavilhão brasileiro em um mastro improvisado no tronco de uma árvore, enquanto uma banda militar tocava o Hino Nacional. Depois, descerrou uma placa de bronze incrustrada no tronco de uma grande castanheira com cerca de dois metros de diâmetro, na qual estava inscrito: "Nestas margens do Xingu, em plena selva amazônica, o Sr. Presidente da República dá início à construção da Transamazônica, numa arrancada histórica para a conquista deste gigantesco mundo verde" (FOLHA DE SÃO PAULO, 1970).
\end{abstract}

A afirmativa demonstrava a representação da rodovia para o cenário nacional, uma arrancada para a conquista do gigantesco mundo verde, a temida floresta amazônica seria transposta por uma estrada que ligaria norte e nordeste de ponta a ponta, e o povoamento que deixaria de se estender somente ao longo $\operatorname{dos} \operatorname{rios}^{9}$ e se realizaria de forma definitiva as margens da estrada, estabelecendo assim os imigrantes como precursores de uma nova e última fase da integração da Amazônia.

\footnotetext{
${ }^{8}$ A ideia da Amazônia como um vazio demográfico, do famoso "terra sem homens para homens sem-terra", desconsiderava as populações tradicionais que nela habitavam. Sobre o tema consultar Souza (2015).

${ }^{9}$ Sobre o tema consultar Cunha (2006).
} 
Neste ponto, vale ressaltar a afirmativa de Sayad (1998), que fala que não há discurso sobre imigração que não apelem para as boas intenções e os bons sentimentos, para os interesses simbólicos ligados a eles. Deste modo, a forte propaganda, os discursos acabaram por criar/recriar no imaginário de muitas famílias a ideia de um recomeço, da Transamazônica como uma verdadeira "terra prometida" ${ }^{10}$, como se pode ver no trecho do seu discurso do Presidente Médici, na Reunião Extraordinária da SUDAM, em 08 de outubro de 1970, mencionado na reportagem do jornalista Luiz Toledo Machado:

\begin{abstract}
Vez por outra quase sempre vindas do estrangeiro, debatem-se as idéias de planos milagrosos para o despertar da Amazônia que, se nem sempre se mostram válidos, viáveis e coerentes, ao menos dizem do interesse estrangeiro sobre a terra prometida e nos acedem o brio nacional[...] (MACHADO, 1970, p. 02, grifo nosso).
\end{abstract}

Assim, com o Presidente e membros da equipe de governo à frente dos discursos otimistas, a Transamazônica surgia e ressurgia como um dos assuntos mais badalados nos primeiros anos da década de 1970 no país, tendo a colaboração da grande mídia que de acordo com o Historiador Magno Michell Marçal Braga (2015), foi determinante na construção de uma imagem positiva do governo, com a utilização de propagandas nos mais diversos veículos de comunicação, o que contribuía para cristalizar na memória popular a construção da Transamazônica como pedra fundamental do "Brasil Grande", slogan utilizado pelo governo e repetido pela grande imprensa.

Para o historiador, o governo entendia que deveria existir uma relação de mão dupla entre a mídia e o Estado, o que na prática poderia se converter em uma espécie de prostituição midiática, em que mesmo os jornais menores, por ideologia, troca de favores ou sob os riscos de perseguição corroboram da mesma forma que o projeto político econômico do governo.

Além da "parceria" da mídia, também fortalecia a comoção popular em torno da abertura de uma rodovia no meio da selva amazônica, o momento próspero que o país atravessava, decorrente principalmente dos altos índices de crescimento da economia que ficou conhecido como milagre econômico ${ }^{11}$, um período de afirmação do regime militar instaurado, em que o governo com obras faraônicas passava a imagem de um país que avançava rumo a se tornar uma potência mundial.

\footnotetext{
${ }^{10}$ É o termo utilizado para descrever a terra oferecida ou dada por Deus aos israelitas. Sobre o tema consultar A Bíblia Sagrada (1993).

${ }^{11}$ Milagre Econômico é resultado de um conjunto de medidas governamentais que elevaram o crescimento do Brasil durante o período da Ditadura Militar, mais precisamente durante os anos 1969 e 1973, no mandato do general Emílio Médici. Sobre o tema consultar Silva (2010).
} 
Assim, a propaganda, a badalação, o momento positivo, a situação de miséria dos nordestinos a época e as promessas em torno da rodovia, foram fatores decisivos para que famílias migrassem para a Amazônia atrás de um recomeço, de uma vida melhor, ou mesmo em busca de uma "terra prometida", visão que se fortalecia no imaginário nacional. $\mathrm{O}$ historiador César Augusto Martins de Souza (2015), pesquisador que discute a construção e colonização da rodovia na década de 1970, afirma que a ideia da Amazônia, como terra do Eldorado, lugar de riquezas incontáveis que deveria ser ocupada e conquistada pela nação brasileira era uma visão consolidada no país.

Diante de tal conjuntura, a região que por vezes assustava pela imensidão da floresta, também motivava por suas riquezas, por seus minérios, por sua biodiversidade, por rios de águas cristalinas, que agora poderiam ser "ocupados" de forma definitiva "numa arrancada para conquista do imenso mundo verde", que abertura da rodovia em meio à selva amazônica representaria, proporcionando assim a conquista da Amazônia por brasileiros, como discursava o presidente Médici.

Com isso, a partida de migrantes motivados em busca do sonho da terra, ou mesmo desse Eldorado ${ }^{12}$ na Transamazônica, era fonte de constantes publicações, a exemplo do jornal Folha de São Paulo de 17 de outubro de 1972, sobre o título "Na Amazônia, um milhão de novas famílias até 82":

\begin{abstract}
Doze famílias paulistas partiram ontem para Santarém, a caminho de Altamira, na Transamazônica. Outras doze partiram hoje, em um avião da VASP e vão se juntar as 131 deste estado que foram para o Norte no início do ano. Segundo os planos do governo federal, dentro de dez anos a Amazônia estará abrigando um milhão de novas famílias, aproximadamente 5 milhões de pessoas. Ao chegar à região, o colono hospeda-se na agrovila até a escolha de seu lote de 100 hectares. Durante os seis primeiros meses recebe o salário mínimo da região - Cr\$206 - para as primeiras despesas. A compra de ferramentas e sementes é financiada pelo Banco do Brasil pelo prazo de 20 anos a partir da primeira colheita. (FOLHA DE SÃO PAULO, 17 de Outubro de 1972, p. 01).
\end{abstract}

Desta forma, a colonização da Transamazônica entrava na ordem do dia das discussões em âmbito nacional, trazendo em reportagens como a supraditos números que impressionavam e visavam demonstrar que finalmente o "vazio" amazônico seria transposto. Outro mecanismo usado para atrair famílias para a colonização, também referido na citação acima, eram os benefícios e as condições prometidas para os colonos migrantes, que reforçava

\footnotetext{
${ }^{12}$ Cidade ou país fictício que exploradores do século XVI afirmavam existir na América do Sul inicial maiúsc.2 p.ext. local pródigo em riquezas e oportunidades; esp. el dorado no sentido de 'o dourado', expressão us. por Orellana para nomear um país de extrema riqueza na América do Sul.
} 
o imaginário acerca da busca pela terra, que para muitas famílias em situação de miséria era o caminho ou o único caminho a seguir, a chance de um recomeço.

Com a chegada dos migrantes e transcorridos os anos iniciais da colonização da rodovia, as propagandas, e principalmente as reportagens que demonstravam a motivação dos agricultores em migrar para a Transamazônica, assim como os vários benefícios que os colonos teriam ao se estabelecerem em solo amazônico, sofreram alterações importantes. Acompanhando o declínio do milagre econômico, os discursos utópicos e otimistas que eram maioria no início da década de 1970, deram lugar, em vários casos a críticas enfáticas sobre a consecução do projeto, principalmente com as denúncias dos colonos assentados e de reportagens que outrora vangloriavam o empreendimento.

Sobre isto, um dos exemplos que pode ser dado é um depoimento em tom de denúncia do agricultor Justino Ananias Menezes, na reportagem de Ricardo Carvalho e Gilberto dos Santos publicada no Jornal Folha de São Paulo na edição de 08 de outubro de 1978:

Colocavam a gente no caminhão e entravam pelos picos (picadas) para escolher um lote o meio do mato", conta seu Justino. O colono, ao ser informado que aquele lote seria seu, saltava do caminhão e tomava posse da terra. Detalhe casa só a agrovila, distante às vezes 10 quilômetros do lote, o que obrigava o colono a caminhar pelo menos 20 quilômetros por dia. Contando ida e volta ao lote. A primeira providência era, portão, a construção de um barraco para alojar a família. E não existia também estrada para o escoamento da produção (CARVALHO, 1978, grifos nossos).

Em outro trecho da mesma reportagem seguem as denúncias e o desabafo de outro agricultor:

\begin{abstract}
Já foram em número maior, Muita gente que veio a primeira leva lá pelos idos de 71/72, como o Chico Garçom, Manuel da carroça, Manuca, Antônio quiquiqui (que era gago) e Tetéu já voltaram para as suas cidades, perdidas em algum ponto do nordeste[...]. Os que vivem as vicinais - que eles chamam de travessão - convivem com as nuvens de pium (versão amazônica - no tamanho e a ferocidade - do osso borrachudo) e com os seis meses de inverno de abundantes chuvas; estão endividados o Banco do Brasil e alguns só não vão embora porque não apareceu ainda ninguém que ofereça um preço razoável pelo lote (50 mil cruzeiros por exemplo). Luis Miguel dos Santos é um deles: “[...] O banco deu empréstimo, mas a gente não tem como pagar, que vem sempre a colheita presta ou então não tem como levar o nosso produto para a estrada; não tem médico perto, não tem técnico para orientar, não tem escolas para os meios; tem a terra que é bom, mas se não fosse tanta promessa eu não tinha vindo, não que não tinha precisão [...]" (CARVALHO, 1978, grifos nossos).
\end{abstract}

Assim, passada a fase da angústia da conquista da terra prometida, os discursos e reportagens de jornais passaram a apresentar também os colonos na Transamazônica diante de obstáculos nem sempre transponíveis. A distância entre as casas da agrovila e o lote, a falta de estrada para escoamento da produção, a qual era vendida quase sempre para intermediários, a 
consequente evasão de muitos agricultores que voltavam para seus Estados de origem, os piuns que assolavam os colonos dificultando sua labuta, as dívidas com o Banco devido à falta de condições de pagar as parcelas acordadas, eram algumas das mazelas propagadas como barreiras que dificultavam a vida dos colonos às margens da rodovia.

Para essa questão, Braga (2015) afirma que nesse processo de assentamento das famílias na Transamazônica, além mal gerido, houve também um erro de execução, já que uma reforma agrária não pode estar condicionada às diretrizes de Bancos financiadores e suas estratégias de lucratividade, privilegiando o latifúndio em detrimento da pequena propriedade. Desta forma, para os fazendeiros e colonos de maiores condições financeiras as chances de sucesso eram maiores, tendo em vista as condições de acesso ao maquinário e às condições para o escoamento da produção, além de não serem dependentes de financiamentos bancários.

Outro problema na execução do projeto também considerado por Braga (2015) é a questão do solo, pois para o historiador os colonos em terras poucos férteis tinham que atender as mesmas exigências dos poucos que eram privilegiados tendo seu lote localizado em áreas férteis. Tal problemática do solo era intensificada devido à falta critérios de seleção dos agricultores em que comumente trazia às margens da Transamazônica, pessoas despreparadas para a lida com a terra, pois segundo Goodland (1975), a colonização da Amazônia dava-se por camponeses com pouquíssima experiência em qualquer tipo de atividade agrícola.

Desta forma, a falta de experiência, a infertilidade dos solos, dívida com o banco, dificuldades de adaptação e as demais questões aqui apresentadas, dividiram ou mesmo ganharam espaço nos debates acerca da Transamazônica na segunda metade da década de 1970 e início da década de 1980.

Assim, esse movimento apresentado acerca da migração da Transamazônica foi explorado sobre diversos pontos de vista, inclusive o da literatura. Dentre os escritores que se destacaram por apresentar obras cujo enredo discutiu a referida temática na década de 1970, destaca-se Odette de Barros Mott, com a obra A Transa Amazônica (a grande ilusão), a qual com base na contextualização feita aqui, será analisada a seguir.

\section{MIGRAÇÃO E COLONIZAÇÃO DA TRANSAMAZÔNICA EM ODETTE MOTT}

Odette de Barros Mott, ou simplesmente Odette Mott, nasceu em Igarapava, interior de São Paulo, em 24 de maio de 1913 e faleceu em São Paulo, em 1998. Uma prestigiada escritora que se dedicou à literatura infanto-juvenil, iniciando sua produção no início dos anos de 1950 com temas voltados ao público infantil, com enredos breves, ingênuos e divertidos. 
A escritora ganhou destaque, com publicações para o público juvenil, inclusive sendo premiada por instituições como a Academia Brasileira de Letras e a Fundação Educacional do Distrito Federal. Em 1970 lançou o livro Justino, O Retirante, abordando fatos reais e do cotidiano para conscientização do seu público, que se estabeleceu como um marco importante para a literatura infanto-juvenil, em que buscou explorar o "realismo documental", que notabilizou como uma das características mais relevantes de sua produção.

Um exemplo de tal característica da escritora é a obra foco desta abordagem A Transa Amazônica (a grande ilusão) (1979) ${ }^{13}$, uma vez que a escritora explorou o cotidiano do processo de colonização da rodovia, demonstrando as partidas e chegadas, a vida dos imigrantes nos primeiros anos nas terras e agrovilas que recebiam do governo por intermédio do Incra, expondo fatos, problemas, mazelas sociais que eram notícia, se valendo assim do realismo documental.

A referida narrativa apresenta três momentos peculiares: primeiramente retrata a família do agricultor Isório na vida sofrida no Estado de Sergipe, às margens do Rio São Francisco, trabalhando de "sol a sol" como meeiro na plantação de arroz da fazenda do seu compadre Juvêncio; logo após, o momento em que Lindauro, o filho mais velho de Isório, começa a ter contato com a cidade, Parapitinga, e conhece os amigos Zezé e Arivaldo iniciando o sonho da Transamazônica; e o terceiro, com a migração das famílias para o Estado do Pará, em busca de terra e uma vida digna na Transamazônica, onde é narrada a labuta na agrovila e lotes.

O tempo histórico da narrativa é a abertura da rodovia Transamazônica na década de 1970, com o narrador onisciente descrevendo sentimentos e pensamentos das personagens, e apresentado com detalhes todos os aspectos da trama, que levam a família de Isório e amigos para as terras às margens da rodovia, que será problematizada a seguir.

\section{A PARTIDA E A CHEGADA À TRANSAMAZÔNICA}

Similarmente às várias histórias de nordestinos que migraram motivados pela a abertura da Transamazônica, o enredo de a A Transa Amazônica (a grande ilusão) inicia apresentando a situação de miséria em que vive a família do Agricultor Isório, sem

\footnotetext{
${ }^{13}$ Transa-Amazônica (1973), que em sua $6^{a}$ edição revisada e com um final menos otimista para os personagens, passou a ser intitulada A Transa Amazônica (a grande ilusão) (1979). Na $6^{\mathrm{a}}$ ed., A GRANDE ILUSÃO, o relato autobiográfico desaparece e as cinco últimas páginas da narrativa original transformam-se em quarenta e duas, onde a odisséia da Transamazônica continua. Neste acréscimo final, vemos que, a par dos raros que conseguem se firmar nos lotes de terras que receberam, a maioria é esmagada pelas condições adversas em que ali se encontravam (COELHO, 2006, p. 750).
} 
perspectivas para o futuro. Desta forma, o leitor é levado a refletir sobre essa situação logo nas primeiras linhas da narrativa, quando o narrador faz uma descrição de Isório:

\begin{abstract}
Bens - Quando morrer, legará à viúva e filhos: a) calção esfarrapado com o qual vive a lama a plantar arroz e cultivá-lo; b) a enxada que é sua a quinze anos, com a qual faz o socado da macaxeira; c) o tapiri coberto e feito de folhas de babaçu; d) a mulher viúva, sem dentes, velha, empaludada; e) os seis filhos, dos quais somente dois ajudam a cuidar do arroz; f) duas cuias onde bebe a água adoçada com rapadura e nos dias de fartura um café ralo; g) a facoa - sua amiga íntima e permanente. Com muito amor a carrega sempre atravessada no cós da calça (MOTT, 1986, p. 02).
\end{abstract}

A situação retratada acima é reforçada durante a primeira parte da trama, em que é enfatizada a situação decadente do agricultor e sua família, pessoas acostumadas por gerações a trabalhar simplesmente para sobreviver, pois a realidade em que vivem lhes parece a única realidade possível, uma vida sofrida, de analfabetismo, submissão, precárias condições de moradia, saúde, alimentação, não tendo sequer um documento de identificação, um sobrenome.

Com isso, seguindo os postulados de Haesbaert (2005) e analisando o movimento proposto na trama, pode-se afirmar, que apesar do vínculo espacial de gerações, a família de Isório vive uma desterritorialização, tendo em vista as condições precárias de vida, pois:

\begin{abstract}
Aliás, devemos acrescentar que nem mesmo a mobilidade espacial é, por si só, um indicador de desterritorialização: muitos grupos podem estar desterritorializados sem deslocamentos físico, sem níveis de mobilidade espacial pronunciados, bastando para isso que vivenciem uma precarização das suas condições básicas de sobrevivência. Habitantes antigos de uma favela podem estar tão desterritorializados quanto migrantes pobres em constante deslocamento (HAESBAERT, 2005, p. 39).
\end{abstract}

Isório trabalha de meeiro para seu compadre Juvêncio no arrozal, initerruptamente, com ajuda de dois de seus filhos, os gêmeos Neco e Rosa de onze anos, pois os dois menores não têm condições de ajudar e os mais velhos, Lindauro e Rialva, trabalham de graça para o patrão, o compadre Juvêncio, já que para o agricultor, afilhados devem obrigação para com o padrinho, e assim Isório labuta, vendo na história de seu pai a sua história, e na sua a perspectiva para seus filhos: trabalhar para patrão com sua parte na safra dando mal para pagar a dívida do Armazém:

Isório, desde que se lembra, sempre viveu essa vida do arrozal, até lhe parece que são a mesma coisa, ele, o arrozal, no mesmo destino. Vai pensando enquanto trabalha: é assim mesmo, quando pequeno o pé na muda, tenro, fraquinho. Vai crescendo, crescendo, ele também, Isório, cresceu. Os filhos, ah! Esses bem comparando são os cachos! (MOTT, 1986, p. 08).

Uma vida sem horizontes, sem um sonho a seguir, é como a vida do agricultor Isório é descrita nas primeiras páginas da narrativa. Tal descrição constrói uma ambientação similar 
com as histórias sobre a seca que levou milhares de nordestinos para as margens da Transamazônica em busca de um futuro melhor, e prepara o leitor para um movimento comum nos processos migratórios rumo à Amazônia no século XX e por que não no mundo, em que calamidades, situações difíceis, fazem as pessoas buscarem outro direcionamento para suas vidas através da migração. Sobre isso Ianni (2004) diz:

Esta é uma lição da história: na sociedade mundial, assim como na sociedade nacional, o migrante, continua a ser tangido por situações e acontecimentos, como que fustigado pelos ventos. Pode ser apenas um, solitário, retirante, perseguido, ambicioso, viandante; mas podem ser muitos milhares, tangidos por desastres ecológicos e epidemias, guerras e revoluções, xenofobias e etnicismos, racismos e fundamentalismos, em busca de trabalho, refúgio, raízes, paz (IANNI, 2004, pp. 100-101)

Desta forma, seguindo os postulados de Ianni (2004) e a história migratória para a Amazônia, pode-se dizer que Odette Mott busca uma primeira marca identitária dos migrantes da Transamazônica, que é a problematização da vida destes na sociedade de origem, com situações de calamidade, de extrema pobreza, que somadas à oportunidade de um rumo melhor, faz pessoas partirem em busca de trabalho.

Após as primeiras páginas em que é apresentada a situação da família de Isório, a narrativa foca no filho do agricultor, Lindauro, que passa a protagonizar e problematizar a vida da família submissa às vontades do padrinho. Um momento importante desse movimento é a primeira vez que o rapaz vai à cidade:

\begin{abstract}
Ali, preso ao padrinho por obrigação que os pais, tão sem vivência tinham criado ao seu redor, como alta muralha a separá-los de todas as outras possibilidades, preso à lama, aos caranguejos, ele, Lindauro, sente-se também prisioneiro das próprias limitações impostas pelo seu pouco contato com o mundo. É um prisioneiro do seu próprio meio e de sua ignorância. Mas agora, sacudido as estruturas, desde que fora a cidade, tudo que vira e ouvira toma corpo e forma em sua cabeça jovem. É preciso romper as amarras e largar, rio abaixo, acompanhar as águas, longe, bem longe dali (MOTT, 1986, p. 47).
\end{abstract}

Com a ida à cidade, Lindauro percebe e enxerga um mundo a sua frente, pois, a vida que ele e sua família vivem é apenas uma possibilidade, e talvez a pior, há outras vidas, há esperança, é possível viver bem e de uma forma digna. Assim, com ajuda de seus novos amigos, da cidade, Parapitinga, Zezé e Arivaldo (filhos de seu João), o rapaz vê em tudo que o padrinho faz, o patrão Juvêncio, exploração, no Armazém, no trabalho, nas cobranças e nas condições precárias vividas na lama ${ }^{14}$.

\footnotetext{
${ }^{14}$ Nome dado ao lugar em que Isório e sua família plantavam arroz na fazenda do Juvêncio, também chamado na narrativa de brejo ou lagoa, consultar Mott (1986).
} 


\title{
4. EM BUSCA DA TERRA PROMETIDA
}

Lindauro volta outras vezes à cidade aproveitando os mandados do padrinho, e assim surge na narrativa o sonho de migrar para a Transamazônica metamorfoseada de uma verdadeira terra prometida. A rodovia aparece pela primeira vez na trama no seguinte tópico:

\begin{abstract}
- Angustia não, seu João, conto tudo o que sei. Estava mesmo ansioso para vir aqui conversar com vocês. Não sei se é verdade, mas andam falando por lá de uma estrada que vai de João Pessoa pelo norte todo, cortando tudo, as matas, os rios, os igarapés. Uma estradona de quilômetros e quilômetros, abrindo sem medo os caminhos, como nosso amigo Chico. E que, lado a lado da estrada, o governo vai dar terras para quem quiser plantar. Terra boa para o feijão, arroz e milho (MOTT, 1986, p. 69).
\end{abstract}

Inicia, então, um movimento comum aos fluxos migratórios e que em outros momentos motivaram muitas famílias a migrarem para a Amazônia, a idealização de uma vida melhor, de um lugar bom, diferente, um Eldorado, semelhante ao exposto no passado, na propaganda migratória da Amazônia na Espanha ${ }^{15}$, trazendo-a como uma verdadeira terra prometida, "uma terra que mana leite e mel" ${ }^{16}$. Abaixo, Arivaldo e Lindauro conversam sobre a Transamazônica:

- Sim, o Zezé foi a Aracaju e tomou as informações. Ele disse que a estrada Transamazônica, nossa estradona, já está cortando tudo, passando por cima de rios, varando montanhas. Disse que não há igarapé que a segure, nem onça que impeça os mateiros de ir cortando mata.

- E as terras?

"-As terras existem, sim, e das boas. Boa para tudo, disseram que "é formosa e boa e tudo se plantando dá”, foi essa a informação.” (MOTT, 1986, p. 84, grifos nossos).

Reforçando a ideia de Eldorado, de terra prometida, a narrativa segue apresentando elementos que caracterizam a melhor visão possível das terras às margens da Transamazônica, e assim atrair migrantes para colonizar a Amazônia. No trecho supracitado, por exemplo, há a menção à expressão "e tudo se plantando dá", utilizada para se referir a terras férteis e exuberantes e que é conhecida por ser alusão à Carta de Pero Vaz de Caminha $^{17}$ ao Rei de

\footnotetext{
${ }^{15}$ O livro El Pará, de 1985, trazia um discurso de convencimento, prosperidade e muita fortuna aos imigrantes espanhóis. A organização do texto propõe ao leitor a ideia de que havia na Amazônia uma grande chance do indivíduo imigrante tornar-se um agricultor, um comerciante ou até um grande homem de negócios. Sobre o tema consultar Smith Júnior (2011)

${ }^{16}$ Uma referência à terra prometida por Deus aos Israelitas como sinônimo de fertilidade, Bíblia (1993).

${ }^{17}$ Em $1^{\circ}$ de maio de 1500, Pero Vaz de Caminha escreveu ao rei dom Manuel o relato da viagem a então Terra de Santa Cruz (Brasil), com o seguinte trecho: "Nela, até agora, não pudemos saber que haja ouro, nem prata, nem coisa alguma de metal ou ferro; nem lho vimos. Porém a terra em si é de muito bons ares, assim frios e temperados (...). Águas são muitas; infindas. E em tal maneira é graciosa que, querendo-a aproveitar, dar-se-á nela tudo, por bem das águas que tem". Sobre o assunto consultar Marton (2011).
} 
Portugal Dom Manuel, em 1.500, por ocasião da "descoberta" das terras do Brasil, para descrever a riqueza das terras ora descobertas.

Ademais a questão metalinguística, os trechos que antecedem a migração dos personagens e remetem à Transamazônica, também reforçam o recomeço que para os personagens simbolizava a migração para as terras às margens da rodovia:

- Agora, enquanto a cabeça funciona, vamos falar sobre nossa estradona! O Zezé veio, esteve lá com o Bento, visitou a sala onde trabalha o pessoal do INCRA. Lá que ele deu nosso nome, disse que viu umas fotos da cidade de Altamira, no Estado do Pará. Lindauro ouvia tudo como quem assiste a um ato religioso: com fé, amor, e esperança (MOTT, 1986, p. 92).

Esperança, fé, amor, eram alguns adjetivos ligados à ideia de migração para a estrada que ambientavam os sonhos de várias famílias do Nordeste e de outras regiões do país, com um histórico de exploração, pobreza, seca e, como as famílias na obra de Odette Mott, sem chão para chamá-lo de seu. Deste modo, a proposta do governo era semelhante à aliança de Deus com o povo de Israel, como se Senhor tivesse ouvido o seu clamor e lhes ofertado a propriedade da terra de que necessitavam e sonhavam.

\begin{abstract}
Para os que saíram das terras secas do Nordeste e vieram para a Amazônia, onde "há cursos d'água, fontes e lagos" abundantes, esta é, sem dúvidas, a terra que procuram e aquela que, em algum momento da história, lhes foi prometida. [...] O mito da terra prometida é recolocado cotidianamente na vida dos camponeses da região e, muitos deles, que após várias migrações saíram do nordeste, em busca de terra na Amazônia - alguns há mais de 30 anos - se identificam com aqueles que saíram com Moisés pelo deserto em busca da terra prometida (LOUREIRO, 2015, p. 95).
\end{abstract}

Assim, famílias nordestinas como a de Isório que marcadas por um horizonte de exploração e sem perspectivas, indubitavelmente viram em terras oferecidas pelo governo a esperança de conquistar um lugar melhor para viver. Desse modo, pode-se afirmar que em especial na década de 1970, os colonos que vieram para a Amazônia em busca de Terra fizeram movimento similar com a passagem bíblica de Moisés e, portanto, um movimento também lembrado por Odette Mott na sua narrativa, que retratou a empolgação, os planos, os sonhos de uma terra boa, farta, para um recomeçar dos personagens.

Paralelamente, para ratificar a ideia supracitada, vê-se na passagem bíblica uma ideia semelhante, uma vez que o povo vivia em condições de opressão e miséria e o SENHOR lhes reserva uma Terra boa, como segue:

[...] 7Disse o SENHOR: "Certamente tenho observado a opressão e a miséria sobre meu povo no Egito, tenho ouvido seu clamor, por causa dos seus feitores, e sei o quanto estão padecendo. 8Por esse motivo desci a fim de livrá-los das mãos dos 
egípcios e tirá-los daqui para uma terra boa e vasta, onde mana leite e mel: a terra dos cananeus, dos hititas, dos amorreus, dos ferezeus, dos heveus e dos jebuseus. Porquanto agora o clamor dos filhos de Israel chegou até mim, e também contemplo a opressão com que os egípcios os estão submetendo e fazendo sofrer.[...] (BÍBLIA, 1993, p. 41, grifos nossos).

Portanto, para os oprimidos e em miséria, o senhor ofertou uma terra que "mana leite e mel", e para a família sofrida e explorada dos agricultores da trama em questão, esta era a Transamazônica. Por mais que essa terra não se consolide em sua plenitude ao final da trama, essa foi à forma como foi apresentada a "estradona", um lugar para os sofridos onde o recomeço é possível, o que foi uma constante na abertura da Transamazônica, marcá-la como uma verdadeira terra prometida, um lugar para plantar, colher, viver feliz. Deste modo os benefícios propostos pelo governo são apresentados, e as personagens vivem como em um mundo paralelo, sonhando com a Transamazônica:

\begin{abstract}
As terras são em volta da agrovila, algumas às margens da estradona. São 100 ha, mano, a gente pode plantar milho, arroz, feijão, cana. Tudo da gente, para pagar um tiquinho em 20 anos! Quando vai, o governo com um salário mínimo durante seis meses, até a colheita da safra. Sabe que lá já tem gente colhendo milho? Vi fotografia do milharal tão verde, tão bonito! Da boca de Arivaldo pareciam sair as espigas douradas, os cachos de arroz, a macaxeira. Eles viam tudo isso através das palavras do moço e da esperança de dias melhores que traziam no peito (MOTT, 1986, p. 92).
\end{abstract}

Pode-se dizer neste ponto que milhares de migrantes que idealizaram e esperaram a ida para a Transamazônica, diante de todos os benefícios que se apresentavam, e sonharam juntos como as famílias da trama de Odette Mott, passaram a viver uma espécie de territorialidade:

\footnotetext{
Outro indicador de que a desterritorialização não está presente de forma dominante em todo processo migratório é o de que a territorialidade pode ser vivenciada também no imaginário dos grupos sociais. Os judeus não carregaram consigo durante séculos a "territorialidade" da Terra Prometida? O Peso da dimensão simbólica dos territórios na atual dinâmica social mundial deve ser sempre destacado (HAESBAERT, 2005, p. 43).
}

Assim, o imaginário instaurado durante a segunda metade da trama em que as benesses da migração para a Transamazônica são expostas, cria, de certa forma, um território simbólico que as famílias se apegam, vivem e respiram, não vendo a hora de partirem em busca da utopia da terra.

Essa idealização é ultrapassada com a terceira fase da narrativa, em que as famílias finalmente chegam à Transamazônica e começam a labuta nos lotes. Assim, passados o choque inicial de ter ganhado uma casa na agrovila, um lote para pagar em vinte anos, um 
salário mínimo para os primeiros seis meses, a narrativa em forma de denúncia apresenta várias problemáticas do processo de colonização da rodovia:

Lindauro, Zé, Arivaldo e seu João, com Isório à escuta sem palpitar, trocaram ideias de como resolver o problema das famílias, se permaneceriam na vila ou iriam morar nos lotes. [...] - A família fica aqui, não dá pé pros meninos andar dez quilômetros para vir e dez para voltar. É um estirão grande - diz seu João (MOTT, 1986, p. 122).

Assim sendo, a distância dos lotes para as casas que as famílias ganharam nas agrovilas, foi a primeira dificuldade que teve que ser sanada pelas famílias na narrativa, tendo em vista que, apesar da precariedade das condições em que viviam, nunca precisaram se separar, visto que os lotes eram distantes da Agrovila, em que ficava a casa que as famílias ganharam: - Ao voltarem, Zé e Arivaldo ouviram a mãe queixar-se: — Tão longe, filho, a gente vai se ver nunca, quem vai cuidar d'ocês? (MOTT, 1986, p. 124).

Assim, após a idealização de um território, "a terra prometida", como foi supramencionada as terras às margens da Transamazônica, os indivíduos migrantes continuam desterritorializados, pois, seguindo os postulados de Haesbaert (2005), ao contrário das expectativas, vivenciam uma precarização das suas condições básicas de sobrevivência.

Eles, pobres coitados, num desejo de possuir a terra, pensavam que ali poderiam realizar o velho e tão válido sonho de todo aquele que vive do plantar e colher. Não ter patrão, ter o suficiente para cuidar da própria terra e dos filhos, manda-los à escola e, acima de tudo, ser dono dos seus atos. [...] Sentiam ante a realização e o que sonharam a mata invencível a se impor para seus braços e machado (MOTT, 1986, p. 128)

Destarte, os obstáculos venciam aos poucos o sonho das famílias de Isório e seu João de uma vida diferente na Transamazônica, com terra, casa, e assistência do governo. A situação se complicava com o passar dos dias, era preciso persistir na medida em que as poucas regalias oferecidas pelo INCRA iam se tornando obstáculos a serem vencidos.

Seu João, mais entendido, pois nasceu e foi criado o Recôncavo baiano, indo somente depois de moço para o vale, examina a terra. Colhe um punhado aqui, acolá, espalha a mãos, cheira, prova, sacode a cabeça e termina: - E terra ruinzinha! [...] Mas, aqueles ali, tão sós, tão mínimos, vieram fazer o quê? Terras para homens para homens sem terras!? Estaria certa essa proposição? Terá valor o lote que compraram, sem nem sequer conhecerem o solo se é fértil ou não!? (MOTT, 1986, pp.126-128).

Deste modo, a realidade das famílias pobres e migrantes, de Isório e seu João, como outros casos que aparecem na obra ficcional e nas manchetes de jornais na década de 1970, retratam que no contexto da migração, uma mudança de cidade, estado, país, não necessariamente significa um melhor padrão de vida, uma ascensão social. Em consonância 
com os estudos de Haesbaert (2005), pode-se afirmar que passaram a viver, no contexto da desterritorialização, uma multiterritorialidade ou mesmo uma a-territorialidade insegura, tendo em vista não possuírem condições mínimas para transpor os obstáculos que se apresentam à sua frente e que a mobilidade espacial em nada mudou a sua mobilidade social, ao contrário:

É que os fazendeiros, os cheios da grana estão fazendo - diz um que se encostara à porta e participava da conversa. - Atrás dos lotes 30, mata adentro, fim do mudo, tem campo pronto para receber os talos de cana. $\mathrm{O}$ fazendeiro contratou moradores dos lotes vizinhos, paga, e assim da pros coitado ir vivendo. Ainda foi bom, imagine - continua ele - logo depois das chuvas, a vicinal! Se o pobre diabo conseguir um saco ou dois de feijão, como faz pra trazer ele pra cidade $\mathrm{O}$ tal fazendeiro com o trator abriu caminho, derrubou mata sem dó, com as motos-serra carrega o caminhão de madeira boa, leva pra Altamira e depois traz os talos de cana, tijolos, a casa dele é de tijolo, a dona, mulher dele também anda de saltinhos dentro de casa. Um dia fui lá e ouvi e vi tec-tec de lá pra cá (MOTT, 1986, pp. 148-149).

Assim, seguindo ainda os postulados de Haesbaert (2005), infere-se na narrativa em questão, que as condições precárias e, portanto, a multiterritorialidade insegura, se restringia só às pobres famílias imigrantes, pois, os fazendeiros com condições econômicas, e com muito mais terras, podiam além de fazê-las produzir e tirar altos lucros, não sentiam a intensidade da vida da Transamazônica como as famílias mais pobres. Pois a migração para estes continuava sendo uma forma de auferir lucros, ou seja, para estes a desterritorialização pode ser confundida com uma multiterritorialidade segura.

Devemos optar, então, por utilizar o termo muito mais para os migrantes de classes subalternas em sua relação de exclusão (ou inclusão precária, como propõe Martins) na ordem socioeconômica capitalista do que para as classes privilegiadas, onde desterritorialização, muitas vezes, confunde-se com mera mobilidade física (HAESBAERG, 2005, p. 39).

Desta forma, a narrativa rememora a situação da família de Isório na sociedade de emigração, pois enquanto imigrantes, apesar da mudança espacial e simbólica as mesmas mazelas vividas na lama, na plantação de arroz persistem na Transamazônica, e o Fazendeiro Juvêncio que explorava o trabalho outrora, reaparece com outro nome, em outro lugar, mas sem mudar a relação rico/pobre, explorador/explorado.

Diante disso, a narrativa mostra o insucesso de algumas famílias estabelecidas na agrovila Boa Esperança, que assim como as famílias de Isório e seu João, sofrearam nos primeiros anos com a distância dos lotes e as demais barreiras que se apresentavam na Transamazônica: 
Zé nota e comenta com Arivaldo que nesse ano faltam muitas famílias.

- Que aconteceu com seu Pedro, tão festeiro, e a família? Seu Antônio, seu Franz?

- Foram s'imbora, as mulheres não quiseram morar mais nos lotes. Dois anos de muito sacrifício. Os homens ficar lá sozinhos, também não dá pé. A dívida com o banco crescia, resolveram devolver a terra e voltar (MOTT, 1986, p. 154).

Assim, com o passar dos anos, pessoas de diversas partes do país não suportaram as dificuldades e regressaram para as suas terras, as quais muitas vezes tinham abandonado e se desfeitos dos bens para virem em busca da utopia da terra; como seu Giacomo, que a narrativa apresenta como um paulista filho de italiano, que vivia como Garçom e, motivado por todos os benefícios da estrada, migra para a Transamazônica.

Nesse momento Arivaldo notou a mulher descalça e umas sandálias de salto alto fino, no chão a seu lado.

- São Bom Jesus da Lapa, ela veio com aquilo nos pés e ele de terno. As crianças de tênis. Quanto despreparo, por que vieram, por quê?

[...] - Seu Giacomo, o que o senhor veio fazer?

- Não sei... não sei - e abaixa a cabeça num desespero danado, lágrimas caindo-lhe pelo rosto. - Desgracei minha família, vou ver meus filhos morrerem nesta mata, comidos pelos bichos! (MOTT, 1986, pp. 133-136).

Com a família de seu Giacomo a narrativa ainda há falta de critérios para seleção dos migrantes que viriam "ocupar” a Transamazônica, que deixava margem para a escolha de pessoas sem o devido preparo para enfrentar a agricultura e todos os desafios que se mostravam na empreitada da rodovia. A ideia de povoar aliada à forte propaganda teria motivado pessoas sem experiência, como um Garçom, a se aventurar como voluntário para o plano de colonização da rodovia.

Assim, a narrativa faz várias reflexões com relação à migração para a colonização da rodovia Transamazônica. Entre a esperança de dias melhores e a desilusão das personagens na trama, muitas famílias regressaram devido ao insucesso, para outras, isto não era possível, regressar pra onde? Regressar pra quê? A saída era não pensar em uma saída:

- Sabe, mano, a gente veio de tão longe, com tanta esperança, seu Bento a falar da estradona, e aqui a luta é ainda pior que lá, mais brava. Longe de todos, o que você diz? A tal Transa-Amazônica é mesmo como dizem lá na agrovila, TransaAmargura!

- Voltar? Voltar pra onde? A gente vendeu o sitiozinho, trouxe seu Isório nessa empreitada, ele deixou seu carrasco. Voltar pra onde? Continuar? Com diabo a se meter no meio, com levar quase de graça o que a gente ganhou com sangue? (MOTT, 1986, p. 164).

Desta forma, a utopia de dias melhores na narrativa de Odette Mott, vira a desilusão em que a autora especifica várias mazelas do processo de abertura e colonização da rodovia Transamazônica na década de 1970. A seguir, as considerações finais do presente artigo. 


\section{CONSIDERAÇÕES FINAIS}

No estudo da migração para a Amazônia por ocasião da colonização da rodovia Transamazônica a partir da obra literária A Transa Amazônica ( a grande ilusão), da escritora Odette de Barros Mott, fica perceptível ao leitor o movimento que a narrativa expõe para o fluxo migratório em destaque, em que as ações dos personagens se dividem no movimento de partida, com a apresentação da vida dos personagens e o sonho de conquistar a "terra prometida" e a chegada na Transamazônica, com a vida das famílias nos lotes e agrovila.

Com isso, a análise da obra sob a ótica de autores que discutem a migração, além do contraponto com outras fontes bibliográficas, elucida que a narrativa apresenta uma crítica ao projeto de colonização da rodovia através do contraste entre as condições prometidas para as que de fatos foram oferecidas aos colonos na Transamazônica, que fizeram famílias que migraram em busca da utopia da terra, viverem uma desilusão em solo amazônico.

Deste modo, em A Transa Amazônica ( a grande ilusão), tem-se um exemplo de grandes empreendimentos, frutos de decisões governamentais que atraem ou mesmo visam atrair fluxos migratórios, mas que não são antecedidos de um estudo aprofundado de seus impactos, benefícios e, portanto, não são implementadas as medidas necessárias para a sua eficaz condução, e culminam causando problemas para a população envolvida.

Com a obra em questão, Odette de Barros Mott confirma a sua importância para a literatura nacional, mais especificamente a literatura infanto-juvenil, em que mesmo não sendo uma migrante da Transamazônica, não se eximiu de realizar um trabalho de campo e traduzir na narrativa o compromisso social de sua produção literária. Desta forma, é uma fonte para futuros trabalhos, uma análise de outras obras literárias que trazem como tema a construção e colonização da rodovia, tendo em vista o contraponto que pode ser feito a partir de abordagens e visões diferentes do referido processo.

\section{REFERÊNCIAS}

BECKER, Bertha K. "Geopolítica da Amazônia". Estudos avançados 53 - Dossiê Amazônia brasileira I. São Paulo: Instituto de Estudos Avançados/ USP, jan-abril 2005, p. $71-86$.

BÍBLIA, Português. A Bíblia Sagrada: Antigo e Novo Testamento. Tradução de João Ferreira de Almeida. Edição rev. e atualizada no Brasil. Barueri: Sociedade Bíblia do Brasil,1993. 
BRAGA, Magno Michell Marçal. Rota transamazônica: nordestinos e o Plano Nacional de Integração. Curitiba: Prismas, 2015.

CARVALHO, Gilberto. Na transamazônica, o fracasso de uma colonização (o brasileiro esquecido). São Paulo, 08 de outubro de 1978, p. 10. Acervo Folha. http://acervo.folha.uol.com.br/fsp/1980/09/01/2//4260071. Acessado em 21.01.2017.

COELHO, Nelly Novaes. Dicionário crítico da literatura infantil e juvenil brasileira. $5^{\text {a }}$ ed. rev. atual. - São Paulo: Companhia Editora Nacional, 2006.

CUNHA, Euclides. À margem da História. São Paulo: Martin Claret, 2006.

FOLHA DE SÃO PAULO. Na Amazônia um milhão de novas famílias até 82. São Paulo, 17 de outubro de 1972, p. 1. Acervo Folha. http://acervo.folha.uol.com.br/fsp/1972/10/17/2//4405651. Acessado em 20.01.2017.

GOODLAND, Robert J. A. \& Irwin S. A. A Selva Amazônica: do inferno verde ao deserto vermelho? Tradução de Sônia Regis Junqueira, São Paulo: Itatiaia/ Universidade de São Paulo, 1975.

HAESBAEST, Rogério. Migração e Desterritorialização. In: NETO, Helion Póvoa e

FERREIRA, Ademir Pacelli. Cruzando Fronteiras Disciplinares: Um panorama dos estudos migratórios. Rio de Janeiro: Revan, 2005, p.35-46.

HOUAISS, António. Grande Dicionário Houaiss da língua portuguesa. Rio de Janeiro: Instituto António Houaiss. Disponível em: http://houaiss.uol.com.br/. Acesso em: 17 dez. 2017.

IANNI, Otávio. O imigrante. Capitalismo, violência e terrorismo. RJ, Civilização Brasileira, 2004, p. 91-101.

LOUREIRO, Violeta Refkalefsky. Estado, bandidos e heróis: utopia e luta na Amazônia. Belém: Cultural Brasil, 2015.

MACHADO, Luiz Toledo. A teoria do grande espaço nacional - VI. São Paulo: Folha de São Paulo, 20 de dezembro de 1970, p. 4. Acervo Folha. http://acervo.folha.uol.com.br/fsp/1970/12/20/2//4384166. Acessado em 20.01.2017.

MARTON, Fábio. Em se plantando nada dá: A carta de Caminha estava errada. Plantar no Brasil foi bem mais complicado do que o patriotismo imagina. Dezembro de 2011. Disponível em: http://planetasustentavel.abril.com.br. Acesso em: 12.02.2017.

MOTT, Odette de Barros. A Transa amazônica (a grande ilusão). São Paulo: Brasiliense, 1986.

PEREIRA, Osny Duarte. A Transamazônica - prós e contras. Rio de Janeiro: Civilização Brasileira, 1971. 
SILVA, Tiago Ferreira da. Milagre Econômico. Março de 2010. Disponível em: http://www.historiabrasileira.com. Acesso em: 12.02.2017.

SAYAD, Abdelmalek. A imigração ou os Paradoxos da Alteridade. Tradução Cristina Murachco. São Paulo: Editora da Universidade de São Paulo, 1998.

SMITH JÚNIOR, Francisco Pereira. "Inmigración y Colonización": a propaganda da "Amazônia Brasileira” na Espanha.In: Revista Estudos Amazônicos. Vol. VI, nº 2, 2011.

SOUZA, Cesar Augusto Martins. Memórias da Transamazônica: milagre, fracasso e migração nos anos 1970. In: QUADRAT, Samantha Viz; ROLLEMBERG, Denise (Org.). História e memória das ditaduras do século XX, v2. Rio de Janeiro, FGV, 2015. 